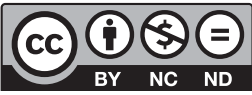

Estudos Teológicos foi licenciado com uma Licença Creative Commons Atribuição - NãoComercial - SemDerivados 3.0 Não Adaptada

http://dx.doi.org/10.22351/et.v60i3.4221

\title{
InferênCias teológicas na Série de TV Luke Cage, da Netflix, E SEus Paralelos COM A TeOlogia Negra de James Cone ${ }^{1}$
}

\author{
Theological inferences in Netflix's Luke Cage TV series \\ and its parallels with the black theology of James Cone
}

\section{Marcelo Ramos Saldanha ${ }^{2}$ Iuri Andréas Reblin ${ }^{3}$}

Resumo: Este artigo apresenta a série Luke Cage (2016), oriunda dos quadrinhos Luke Cage: Hero for Hire, de 1972, fazendo a pergunta pelos elementos da teologia negra da libertação presentes nela, em especial a defendida pelo Rev. James Hal Cone. O argumento deste texto é o de que a série constrói sua identidade a partir da cultura das comunidades afrodiaspóricas nos Estados Unidos, e, dessa forma, a teologia negra e as narrativas da escravidão emergem dessa mesma cultura, aparecendo na obra da Marvel/Netflix como uma crítica autêntica à tentativa racista de definir o estatuto ontológico do corpo negro.

Palavras-chave: Luke Cage. Teologia negra da libertação. Cristologia. Racismo.

Abstract: This article presents the TV series Luke Cage (2016-2018), from the comic book Luke Cage: Hero for Hire, from 1972, asking the question about the elements of Black Liberation Theology present in it, especially the one advocated by Rev. James Hal Cone. The argument of this text is that the TV show builds its identity from the culture of Afro-diasporic communities in the United States, and, thus, black theology and the narratives of slavery emerge from that same culture, appearing in the work of Marvel / Netflix as an authentic criticism of the racist attempt to define the ontological status of the black body.

Keywords: Luke Cage. Black Liberation Theology. Christology. Racism.

1 O artigo foi recebido em 12 de agosto de 2020 e aprovado em 05 de dezembro de 2020 com base nas avaliações dos pareceristas ad hoc.

O presente trabalho foi realizado com apoio da Coordenação de Aperfeiçoamento de Pessoal de Nível Superior - Brasil (CAPES) Código de Financiamento 001.

2 Doutor. Faculdades EST, PNPD/CAPES. E-mail: marcelo.saldanha@gmail.com

3 Doutor. Faculdades EST. E-mail: reblin@est.edu.br 
Nas palavras de Rob Sheffield, em sua coluna sobre cultura Pop na revista Rolling Stone, Luke Cage é "o primeiro super-herói do Black Lives Matter"4. A referência não é gratuita, já que um negro que não pode ser morto a tiros faz um claro contraste com o escândalo dos denominados "homicídios justificáveis" durante abordagens policiais violentas nos Estados Unidos, nos quais a violência é justificada pela cor de pele da pessoa abordada. A série foi lançada dois anos após o assassinato do jovem negro Michael Brown na pequena cidade Ferguson, no Missouri. ${ }^{5}$ Esse assassinato absurdo, de um jovem desarmado e sem antecedentes criminais, demonstrou como as forças de segurança tratam a população negra e como o sistema judicial é conivente com esse racismo estrutural que nega ao povo negro a plena cidadania num país construído em cima do sangue desses. Essa realidade violenta permaneceu fazendo vítimas, tanto que, em 25 de maio de 2020, George Floyd morreu asfixiado pela violência policial enquanto repetia a frase: "Eu não consigo respirar"6.

Casos como esse dão sentido às palavras do escritor norte-americano Colson Whitehead, quando diz que "é possível fugir da escravidão, mas não do racismo"?. Essa frase, por sinal, foi dita numa entrevista concedida durante a sua estada no Brasil, no âmbito da Flip 2018, um evento no qual o tema do racismo e da violência contra a população negra esteve presente de forma significativa. Tal como na terra de Luke Cage, a realidade do Brasil é terrífica e grita. Basta lembrar que, só em 2018, foram 23 mil pessoas negras, grande maioria jovens, mortas pela violência, incluindo aquela promovida pela força policial, como confirmam os dados da ONU Mulheres Brasil, segundo a qual, a cada 23 minutos uma pessoa negra é assassinada no Brasil. ${ }^{8} \mathrm{Se}-$ gundo o Atlas da Violência 2019, divulgado pelo IPEA em 2019, 75,5\% das vítimas de homicídio no Brasil foram negras. Entre 2007 e 2017, a taxa de assassinatos de negros aumentou $33,1 \%$ ante o crescimento de 3,3\% para não negros. ${ }^{9}$ No que tange, também, à vulnerabilidade à violência, "é como se negros e não negros vivessem em países completamente distintos"10. Nesse sentido, é emblemático o assassinato de João Alberto Silveira Freitas, um homem negro que foi espancado até a morte por

4 SHEFFIELD, Rob. 'Luke Cage': Meet the First Black Lives Matter Superhero. Rolling Stone, out. 2016. Disponível em: <https:/www.rollingstone.com/tv/tv-news/luke-cage-meet-the-first-black-lives-mattersuperhero-112895/>. Acesso em: 02 jun. 2019.

5 FAUS, Joan. Decisão sobre caso Michael Brown desencadeia graves distúrbios nos EUA. El País, 25 nov. 2014. Disponível em: <https://brasil.elpais.com/brasil/2014/11/25/internacional/1416878092_531438. html>. Acesso em: 20 nov. 2020.

${ }^{6}$ AUTÓPSIA particular aponta que George Floyd morreu asfixiado por policial. UOL. 01 jun. 2020. Disponível em: $<$ https://noticias.uol.com.br/internacional/ultimas-noticias/2020/06/01/autopsia-particularaponta-que-george-floyd-morreu-asfixiado-por-policial.htm>. Acesso em: 20 nov. 2020.

7 WHITEHEAD, Colson. Colson Whitehead, um dos maiores escritores da atualidade. Entrevista concedida a Jorge Pontual. Milênio - Globo News, 29 de maio de 2017.

8 ONU Mulheres, 2018. Disponível em: <http://www.onumulheres.org.br/noticias/23-mil-jovens-negrosassassinados-por-ano-e-um-escandalo-diz-nadine-gasman-representante-da-onu-mulheres/>. Acesso em: 02 jun. 2019.

9 INSTITUTO DE PESQUISA ECONÔMICAAPLICADA; Fórum Brasileiro de Segurança Pública (Org.). Atlas da violência 2019. Brasília; Rio de Janeiro; São Paulo: IPEA; FBSP, 2019. p. 49.

10 INSTITUTO DE PESQUISA ECONÔMICAAPLICADA; Fórum Brasileiro de Segurança Pública, 2019 , p. 50. 
seguranças do supermercado Carrefour em Porto Alegre/RS na véspera do Dia da Consciência Negra. ${ }^{11}$

Nesse contexto, em que vidas negras são tratadas como se não importassem, um herói negro com força sobre-humana e pele indestrutível já não pode ser considerado um homem invisivel ${ }^{12}$, como na obra de Ralph Ellison, mas como uma estrondosa expressão do poder negro. Se na obra de Ralph Ellison a invisibilidade se dava pela cor da pele, em Luke Cage a pele negra é poder que desafia o sistema necrófilo que até hoje se alimenta dos corpos das pessoas postas à margem. A pele resistente de Cage é, em si, resistência. Desde sua aparição na revista Luke Cage, Hero for Hire $\mathrm{n}^{\circ} 1^{13}$, em 1972, Luke Cage, o primeiro super-herói negro a ter uma revista solo ${ }^{14}$, tornou-se um símbolo não só do povo negro norte-americano, mas de ideias até então estranhas ao universo da HQ. Era o início da era de bronze das histórias em quadrinhos e já não bastava a representação caricata das pessoas negras, como era corriqueiro até então, o contexto exigia um olhar mais atento, principalmente às tensões raciais nos Estados Unidos. ${ }^{15}$

11 VASCONCELLOS, Hygino. Homem negro morre após ser espancado em supermercado de Porto Alegre. UOL. 20 nov. 2020. Disponível em: <https://noticias.uol.com.br/cotidiano/ultimas-noticias/2020/11/20/videomostra-homem-sendo-e-espancado-por-segurancas-do-carrefour-no-rs.htm>. Acesso em: 25 nov. 2020.

${ }^{12}$ Escrito por Ralph Ellison, o romance Invisible Man foi publicado pela primeira vez em 1952. Esse livro é um clássico da literatura americana e apresenta um homem negro invisibilizado por sua cor. (ELLISON, Ralph. O Homem Invisível. Rio de Janeiro: José Olympio, 2013). Na série, ele aparece juntamente com outros clássicos da cultura negra aos 46 minutos do primeiro episódio, antes de uma das rememorações sobre o período de Carl Lucas em Seagate.

${ }^{13}$ Edição de Stan Lee, roteiro de Archie Goodwin, desenho de George Tuska, arte final e Billy Graham e letras de Skip Kohloff. GOODWIN, Archie; TUSKA, George. Luke Cage, Hero for Hire. New York: Magazine Management Co., Inc. 1972. n. 1.

${ }^{14}$ O primeiro personagem negro fixo nos quadrinhos surgiu em 1934, por autoria de Lee Falk. Era Lothar, o companheiro de Mandrake em suas aventuras, um personagem que seguia os estereótipos comuns acerca dos africanos nos comics. Muitos outros personagens negros foram criados, normalmente como auxiliares dos heróis. Somente no início da década de 1960, com a criação de Pantera Negra por Stan Lee e Jack Kirby, temos a criação de um herói negro. Contudo, o príncipe de Wakanda estava inserido na narrativa do Quarteto Fantástico e só ganhou um título próprio em 1973. Na DC Comics, embora a capa de 1971 (Green Lantern v. 2 \#87) traga John Stewart, o lanterna verde negro, esse ainda era um personagem dentro do contexto da Tropa dos Lanternas Verdes. O primeiro herói negro da DC foi Raio Negro, que só teve um título próprio em abril de 1977 (Black Lightning \#1).

15 A Era de Bronze dos Quadrinhos Estadunidenses compreende comumente o período de 1970 a 1985. A delimitação da Era de Bronze varia conforme a discussão teórica em torno dela. Peter Coogan, por exemplo, precisa esse período entre a publicação de Superman n. 233 (1971) até a publicação de Legion of Super-Heroes n. 259 (1980). Cf. REBLIN, Iuri Andréas. O alienigena e o menino. Jundiaí: Paco Editorial, 2015. p. 149. 


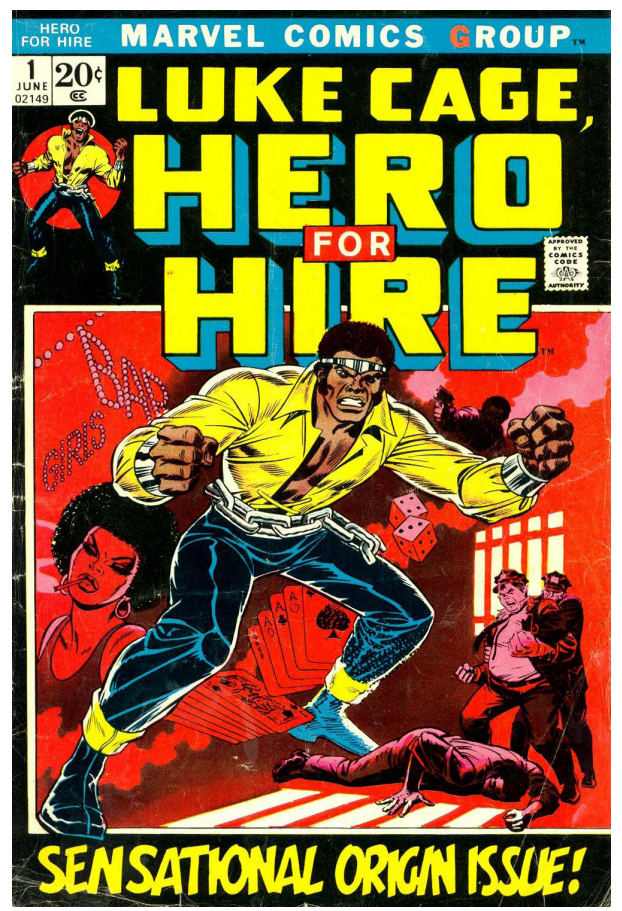

Figura 01: Capa do quadrinho de estreia de Luke Cage

Fonte: GOODWIN, Archie; TUSKA, George. Luke Cage, Hero for Hire. New York: Marvel Comics Group, 1972. n. 1.

(C) 1972 Magazine Management Co., Inc., Marvel Comics Group. Todos os direitos reservados.

Diferente da série de streaming, criada por Cheo Hodari Coker, os quadrinhos de Luke Cage não foram criados por uma pessoa negra, mas, seguindo o que já ocorria com outros personagens negros, Luke Cage foi idealizado por Stan Lee e criado por Archie Goodwin (roteiro) e George Tuska (arte), contando com a contribuição criativa de Roy Thomas. John Romita Jr. foi responsável pela capa da primeira edição. ${ }^{16}$ Roberto Guedes faz uma excelente apresentação desse personagem negro criado por pessoas brancas:

Cage era um marginal de rua preso por um crime que não cometera. Na prisão, foi voluntário em um experimento científico que lhe conferiu uma força prodigiosa e pele quase invulnerável. Ao escapar da prisão, tornou-se um mercenário [...] um verdadeiro

${ }^{16}$ Em novembro de 1973, a edição 15 de Luke Cage, Hero for Hire, traz desenhos do artista negro Billy Graham Jr. A partir desse período a caracterização ganha uma identidade mais autêntica. Antes disso, Graham atuava como arte finalista da revista. GUEDES, Roberto. A Era de Bronze dos Super-heróis. São Paulo: HQ Maniacs, 2008. p. 140. 
herói de aluguel, que cobrava pelos serviços prestados. Uma crítica social aberta, pois mostrava que mesmo no reino "encantado" dos quadrinhos, o caminho do bem para os negros era sempre mais difícil. Cage sempre acabava levando calote ou então, arriscando a vida pelos outros por puro altruísmo ${ }^{17}$.

Embora seguisse a onda do movimento Blaxploitation e tivesse como alvo o público negro estadunidense, a HQ de Luke Cage foi uma das primeiras histórias em quadrinhos que apontava para uma temática negra, visando à ampliação do mercado editorial de quadrinhos. Inspirado em Shaft, o quadrinho trazia uma linguagem repleta de "gírias da malandragem do Harlem"18, bairro conhecido como centro cultural e comercial de afrodescendentes. Nos anos seguintes, sua participação se ampliou a outros quadrinhos da editora, como o Homem-Aranha, nessas circunstâncias, entretanto, sem as "gírias malandras"19. Esse movimento fazia parte da política editorial da Marvel de corresponder às demandas contextuais da época, que exigia uma atenção à "diversidade racial" 20 .

Já a série de TV, lançada 44 anos depois do lançamento da primeira história em quadrinhos de Luke Cage, em outro contexto social e político, emerge de um contexto cultural negro e está mais repleta de referências à cultura afro-americana, quase como numa homenagem à diversidade e à qualidade da produção artística e cultural das comunidades afrodiaspóricas. Nomes como o da pianista Duke Ellington, da folclorista Zora Neale Hurston e dos escritores Donald Goines, Walter Ellis Mosley, Julius Lester, Chester Himes e Langston Hughes, aparecem na boca das personagens da série ou fazem parte direta da narrativa. ${ }^{21}$

${ }^{17}$ GUEDES, 2008, p. 140.

${ }^{18}$ HOWE, Sean. Marvel Comics: a história secreta. São Paulo: LeYa, 2013. p. 134.

${ }^{19}$ HOWE, 2013, p. 142-143.

${ }^{20}$ HOWE, 2013, p. 143. Em um vídeo de explicação sobre o "Método Marvel" de criação de histórias, o Prof. Dr. Amaro Xavier Braga Júnior descreve essa constante em buscar as pautas cotidianas para a composição das narrativas. Cf. PLOT Twist \# 27 - O método Marvel e as dinâmicas editoriais: dimensões conceituais. [Faculdades EST: s. n.], 2020. 1 vídeo (15 min). Publicado pelo canal CultdeCultura. Disponível em: $<$ https://www.youtube.com/watch?v=k5iUAN6HAmI>. Acesso em: 20 nov. 2020.

${ }^{21}$ Um excelente estudo sobre a presença da literatura negra em Luke Cage pode ser encontrado no artigo TOLIVER, Stephanie. Unlockin the Cage: Empowering Literacy Representations in Netflix's Luke Cage Series. Journal of Adolescent \& Adult Literacy, v 61, n. 6, p. 621-630, maio/jun. 2018. 


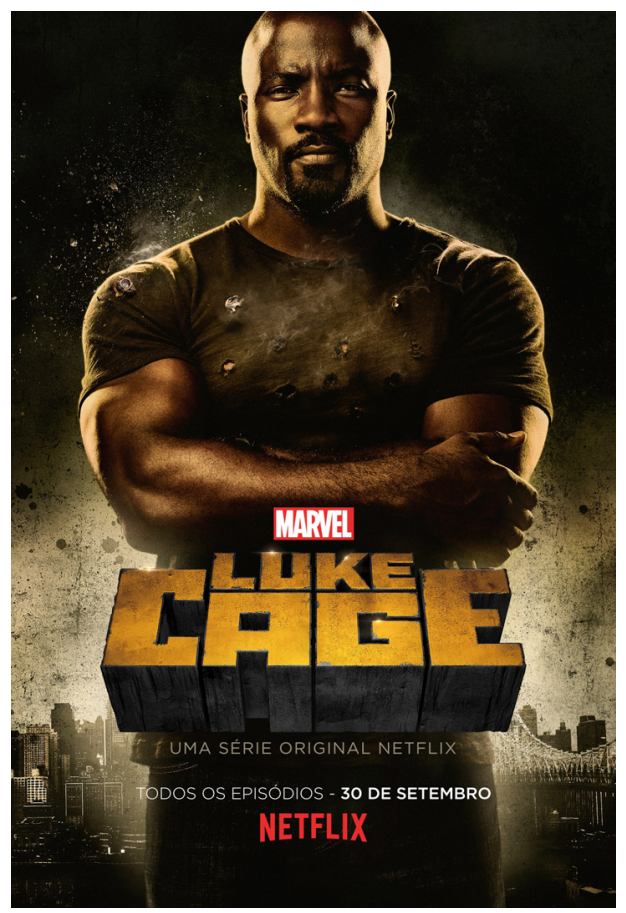

Figura 02: Cartaz promocional da série Luke Cage, da Netflix

Fonte: Divulgação | Reprodução

(C) 2016 Marvel Television and ABC Studios. Todos os direitos reservados.

Numa das conversas entre Pop e Cage ${ }^{22}$, o personagem de Donald Goines, Kenyatta, é usado como exemplo de como o Luke Cage deveria agir. Nessa mesma cena, Cage aparece lendo "Between the World and Me", do jornalista Ta-Nehisi Coates, autor de diversas edições do Pantera Negra. ${ }^{23}$ Nesse livro, Coates apresenta uma história da segregação racial nos Estados Unidos para falar sobre o lugar relegado às pessoas negras na sociedade estadunidense. Na trilha sonora, encontramos desde Nina Simone, cujas músicas aparecem em episódios como Manifest e Soul Brother \#1, até nomes da nova música negra norte-americana. O icônico retrato Biggie na sala de

22 MARVEL - Luke Cage. Direção: Cheo Hodari Coker. Los Gatos: Netflix, 2016. Disponível em: <https:// www.netflix.com/title/80002537?so=su>. Acesso em: 03 fev. 2020. T1, E2, "Code of the Streets".

${ }^{23}$ Algumas das edições escritas por Ta-Nehisi Coates são: Black Panther, \#1-18, \#166, \#167; World of Wakanda \#1-6; Black Panther and the crew \#1-6 (Softcover Preorder). Mais informações sobre o autor podem ser acessadas em: <www.ta-nehisicoates.com>. 
Cottonmouth compõe a homenagem ao hip-hop presente nos títulos dos episódios da série, que são também títulos de músicas da dupla Gang Starr (DJ Premier e Guru). ${ }^{24}$

Num contexto em que a cultura negra dá identidade à série, há que se perguntar como a teologia negra da libertação (TNdL) está inserida na obra e, mais especificamente, como as narrativas textuais e visuais relacionadas à Bíblia e expostas na série apresentam uma hermenêutica comprometida com as slave narratives, tal como lemos nos textos clássicos da teologia negra da libertação (TNdL).

Este estudo parte, metodologicamente, do esboço metodológico para o estudo da teologia do cotidiano, desenvolvido por Iuri Andréas Reblin e utilizado para análise de produções culturais. A escolha pelo método se deu por conta dos limites espaciais do texto e do estudo e por buscar o diálogo direto com a teologia do cotidiano. Por conta da delimitação do texto, não nos ateremos aqui a uma explicação do método, que pode ser antes conferida em publicação à parte. ${ }^{25}$ De todo o modo, sinteticamente, o método consiste em três movimentos:

1) identificar um símbolo, ou um conjunto de símbolos, em uma narrativa (lembre-se de que a religião é, de forma resumida, constituída de um "sistema de símbolos" ou uma "teia de símbolos"). Essa etapa se referia também a olhar o contexto no qual esses símbolos são gestados;

2) compreender como esse símbolo, ou esse conjunto de símbolos, se relaciona com o contexto no qual está inserido, que envolve o contexto narrativo, mas também o contexto de produção e o contexto social. Tratava-se de estabelecer um diálogo entre aquilo que chamei de "a história de um grupo" e o "contexto maior no qual este grupo está inserido" e, por fim,

3) verificar em que medida ou de que forma esse símbolo, ou esse conjunto de símbolos, atua como recusa ou manutenção da realidade, a fim de buscar identificar o coeficiente religioso desse símbolo, digamos assim. Tratava-se de identificar a eventual (ou não) "inflexão de sentido" que o símbolo sofria na narrativa ${ }^{26}$.

${ }^{24}$ Na primeira temporada: 1. "Moment of Truth", 2. "Code of the Streets", 3. "Who's Gonna Take the Weight?", 4. "Step in the Arena", 5.“Just to Get a Rep”, 6. "Suckas Need Bodyguards", 7. "Manifest”, 8. "Blowin' Up the Spot", 9. "DWYCK”, 10. "Take it Personal”, 11. "Now You're Mine”, 12. "Soliloquy of Chaos" e 13. "You Know My Steez". Na segunda temporada: 1. "Soul Brother \#1”, 2. "Straighten It Out”, 3."Wig Out”, 4. "I Get Physical”, 5. "All Souled Out”, 6. "The Basement”, 7. "On and On”, 8. "If It Aint Rough, It Ain’t Right", 9. "For Pete's Sake”, 10. "The Main Ingredient”, 11. "The Creator", 12. "Can’t Front On Me" e 13. "They Reminisce Over You".

${ }_{25}$ O esboço metodológico para o estudo da teologia do cotidiano foi apresentado originalmente na obra REBLIN, Iuri Andréas. Outros cheiros, outros sabores... o pensamento teológico de Rubem Alves. São Leopoldo: Oikos, 2009 e aplicado posteriormente na obra $O$ alienígena e o menino. (REBLIN, 2015). Para um estudo mais aprofundado de um determinado artefato cultural, recomenda-se o uso do método cartográfico-crítico, também desenvolvido pelo autor, que se concentra numa análise pormenorizada de todas as dinâmicas envolvidas no processo de criação artístico-cultural de artefatos culturais, tratando-se, portanto, de um método muito mais completo em termos de análise artístico-cultural. (REBLIN, Iuri Andréas. Histórias em Quadrinhos: perspectivas religiosas e possibilidades hermenêuticas. São Leopoldo: EST, 2019. p.101ss e REBLIN, Iuri Andréas. Método cartográfico-crítico para análise de artefatos da cultura pop a partir da área de ciências da religião e teologia. Rever: Revista de Estudos da Religião, v. 20, n. 3, p. 11-26, set./dez. 2020).

${ }^{26}$ REBLIN, 2019, p.101-102. 
Assim, aplicando o método, iniciaremos com uma apresentação do universo narrativo da série, destacando as diferenças entre a versão da HQ e a produção da Netflix, atendo-nos àquelas que afastam o seriado das representações exógenas ao contexto negro. A partir desse universo, selecionaremos os textos bíblicos, as imagens e as narrativas religiosas presentes na obra a fim de compreender como elas se relacionam com a TNdL e como traduzem hoje uma crítica pertinente à questão da violência racial sistematicamente praticada em países como Estados Unidos e Brasil.

\section{Luke Cage: um novo e velho nome}

O nascimento do personagem Luke Cage se deu num período particular da história estadunidense, quando nas décadas de 1960 e 1970 a luta por direitos civis, principalmente com o surgimento dos Black Power, demonstrou a impossibilidade da invisibilização da população negra. Nesse período, um movimento cinematográfico chamado Blaxploitation forçou Hollywood a abrir-se às transformações políticas que ocorriam no país. Esse movimento cinematográfico de ação afirmativa tirou as pessoas negras da situação de coadjuvantes para visibilizá-las como protagonistas. Eram obras dirigidas e interpretadas por pessoas negras que traziam muito humor, gírias e o uso de clichês para explicitar cinematograficamente a exclusão a que o povo negro estava submetido também nas representações visuais. A Marvel aplicou parte desse princípio à revista Hero for Hire, pois nela havia um personagem negro num universo negro.

Como Luke Cage estourou no cenário dos quadrinhos em 1972, durante a crescente popularidade da mania do fim do blaxploitation no início dos anos 1970, a convenção dita que Cage seja principalmente entendido como o análogo dos quadrinhos à masculinidade negra exagerada exibida no grande tela em quase qualquer variedade de filmes negros que saíram de 1971-1976. Como resultado, Power Man é um dos super-heróis negros mais difamados, porque é visto como um estereótipo blaxploitation. Esse ponto foi impiedosamente exposto pelos criadores de Milestone Comics com os personagens Buck Wild, Mercenary Man, uma sátira velada de Luke Cage da Marvel, Herói de Aluguel. ${ }^{27}$

De todo o modo, apesar de reforçar certos estereótipos, Luke Cage retrata indiscutivelmente a luta de afrodescendentes por igualdade num contexto marcado por preconceito e discriminação.

\footnotetext{
27 "Because Luke Cage burst onto the comic book scene in 1972, during the increasing popularity of the blaxploitation fim craze of the early 1970s, convention dictates that Cage is primarily understood as the comic book analogue to the over-the-top black masculinity paraded across the big screen in nearly any assortment of black films that came out from 1971-1976. As a result, Power Man is one of the most maligned black superheroes because he is viewed as a blaxploitation stereotype. This point was mercilessly driven home by the creators of Milestone Comics with the characters Buck Wild, Mercenary Man, a thinly veiled lampooning of Marvel's Luke Cage, Hero for Hire." (Cf. NAMA, Adilifu. Super black: American pop culture and black superheroes. Austin: University of Texas Press, 2011. p. 53.)
} 
Mas, olhando mais de perto, Power Man é, em muitos aspectos, o super-herói negro mais inerentemente político e socialmente profundo a surgir, independentemente de sua conexão com a moda do filme blaxploitation. Dada a narrativa de origem de Cage como um homem negro injustamente condenado por um crime que não cometeu, ele claramente simboliza a transformação triunfante de um condenado da classe baixa negra em um anti-herói negro politizado em uma escala épica. Mais importante ainda, a mutação literal do personagem de Lucas para Luke Cage está ligada a questões de encarceramento injusto de negros, privação de direitos políticos negros e racismo institucional na América. ${ }^{28}$

Quarenta e quatro anos depois do surgimento nos quadrinhos, o alter ego de Carl Lucas não é mais um herói de aluguel. Se na HQ ele trabalhava para quem lhe pudesse pagar, na série ele se recusa a alugar seus serviços e, usando referência direta ao título dos quadrinhos, no final do primeiro episódio o herói sentencia: “I'm not for hire". Essa, por sinal, é uma diferença curiosa, porque o enfoque nos quadrinhos residia justamente nas dificuldades sociais impostas a afrodescendentes, o que não significa ausência de altruísmo ou ética, mas uma oportunidade de subsistência. De todo o modo, como é comum em todas as narrativas da Marvel ao tematizar a natureza humana, as histórias de Luke Cage brincam com uma ambiguidade moral atribuída ao personagem nos quadrinhos. ${ }^{29}$ Nesse sentido, é emblemática a participação de Luke Cage na "superequipe" dos Defensores (The Defenders), quando o herói negro reclama que suas atividades junto à equipe estavam atrapalhando o seu trabalho de "herói de aluguel". Em resposta, o personagem Falcão Noturno resolveu o dilema dando a Cage um salário fixo por seu trabalho como defensor.

Tal como na HQ, a violência armada e o tráfico de drogas estão presentes na série da Netflix. Contudo, na revista, Cage era filho de um detetive ${ }^{30} \mathrm{e}$, ainda jovem, tornou-se membro de uma gangue do Harlem, bairro em que foi criado. Na série, ele é um ex-policial nascido na Geórgia, filho do pastor batista James Lucas, que tem um filho fora do casamento, o meio-irmão de Cage, chamado Willis Stryker. Na HQ Stryker era amigo e companheiro de crimes de Carl Lucas, que o incrimina, manda-o para cadeia. A traição e a prisão na penitenciária da Ilha Seagate são elementos co-

28 "But upon closer inspection, Power Man is in many ways the most inherently political and socially profound black superhero to ever emerge, regardless of his connection to the blaxploitation film fad. Given Cage's origin narrative as a black man wrongly convicted of a crime he did not commit he clearly symbolizes the triumphant transformation of a black underclass convict to a politicized black antihero on an epic scale. Most importantly, the character's literal mutation from Lucas to Luke Cage is bound to issues of unjust black incarceration, black political disenfranchisement, and institutional racism in America." (Cf. NAMA, 2011, p. 55.)

29 De todos os quadrinhos protagonizados por Cage, o que mais explorou essa ambiguidade foi a minissérie em cinco edições do selo Marvel MAX, destinada ao público adulto. Nessa minissérie, escrita por Brian Azzarello e desenhada por Richard Corben, já encontramos o Luke Cage careca e sem uniforme, tal como na série da Netflix e nas versões atuais na HQ, movendo-se com uma liberdade adulta, explorando ao máximo o humor sarcástico do personagem em seu trânsito pelo submundo do Harlem. Esse último elemento apenas foi apontado na segunda temporada da série Marvel/Netflix.

${ }^{30}$ Mighty Avengers, v. 2 \#11, agosto 2014. 
muns nas duas versões. Lá, Carl fica remoendo a raiva de ter sido incriminado e, em ambas, é atormentado por Albert "Billy Bob" Rackham, um guarda branco e sádico. Na série, contudo, há uma construção narrativa mais ampla, em que o protagonista vira um lutador explorado por Rackham. Na HQ, a perseguição do guarda e a promessa de libertação o conduzem a voluntariar-se no experimento do médico Noah Burstein, que buscava cobaias para experimentos baseados numa variação do soro do "supersoldado". Na série, é Reva Connors quem convence Burstein a tratar Luke com o experimento, após ele ter sido espancado quase até a morte por Shades e outro detento. Tal como na revista em quadrinho, Rackham sabota o experimento no esforço para matar Carl Lucas e, após uma explosão, Carl surge cheio de força e ódio avançando contra Rackham. Sua raiva o fez repetir o gesto do primeiro episódio, no qual dá um soco na parede. Nesse momento, descobre a força sobre-humana recém-ganha, usando-a para abrir um buraco e fugir da prisão.

Essas pequenas diferenças narrativas não afetam o tropo narrativo da origem do personagem e se referem antes à adaptação de linguagem (dos quadrinhos para 0 audiovisual) de contexto (de 1970 para 2016), de intencionalidade narrativa, considerando que uma série de TV, embora possa explorar outros subtemas ou dar outra dimensão contextual, tende a deixar o universo ficcional mais centrado e coeso. De todo o modo, a referência à prisão, constante em ambas as versões (quadrinhos e série de TV), remete diretamente à uma crítica ao sistema penitenciário estadunidense. Nas palavras de Nama:

Essa configuração narrativa é politicamente comovente e bastante atual para a época. Durante o início dos anos 1970, o complexo industrial carcerário dos Estados Unidos estava cada vez mais sendo criticado por discriminação racial e precisava de uma reforma significativa. Soul on Ice de Eldrige Cleaver, junto com Soledad Brother: The Prison Letters of George Jackson e Blood in My Eye de George L. Jackson, trouxeram um holofote nacional para o quebrado e injusto sistema carcerário de América. Além disso, protestos políticos de alto nível em torno dos encarceramentos de Angela Davis, Huey P. Newton, Rubin "Hurricane" Carter e Elmer "Geronimo" Prat empurraram os prisioneiros negros para a consciência americana como figuras políticas e ativistas da prisão. Da mesma forma, não apenas uma variedade heterogênea de presidiários negros se tornou causa célebre para radicais de esquerda brancos e nacionalistas negros, mas suas narrativas de prisão incendiaram a consciência dos prisioneiros para defender condições mais humanas ${ }^{31}$.

31 "This narrative setup is politically poignant and quite topical for the time period. During the early $1970 \mathrm{~s}$ America's prison-industrial complex was increasingly coming under criticism for racial discrimination and was in need of significant reform. Eldrige Cleaver's Soul on Ice, along with George L. Jackson's Soledad Brother: The Prison Letters of George Jackson and Blood in My Eye, brought a national spotlight to America's broken and unjust prison system. Moreover, high-profile political protests around the incarcerations of Angela Davids, Huey P. Newton, Rubin 'Hurricane' Carter, and Elmer 'Geronimo' Prat thrust black prisoners into the American consciousness as political figures and prison activists. Accordingly, not only did a motley assortment of black inmates become cause célèbre for white leftist radicals and black nationalists, their prison narratives ignited the consciousness of prisoners to advocate for more humane conditions." NAMA, 2011, p. 55. 
Uma vez liberto da prisão na Geórgia, no Deep South, Carl Lucas começa os "longos meses de trabalho rumo ao norte" 32 , como quem repete a rota histórica das pessoas escravizadas que seguiam para o norte rumo à liberdade. Sem desfrutar da ferrovia subterrânea ${ }^{33}$, que ajudou muitas pessoas escravizadas nesse processo, Carl Lucas vive à margem, como alguém oficialmente morto, para quem nenhum trabalho era pequeno. ${ }^{34}$ Ao chegar ao Harlem, o ex-detento de Seagate não usa o poder recém-descoberto para vingar-se, mas escolhe trabalhar como zelador na Pop's Barbershop, um refúgio para a violência do Harlem ${ }^{35}$, submetendo-se sem problemas à regra de não falar palavrões no local de trabalho. Ali ele aprende a superar o desejo de "dar o troco", uma referência direta a Malcon X, o militante negro pelos direitos dos afro-americanos que pregava a necessidade de reagir dando o troco às violências racistas. ${ }^{36}$ Nessa direção, busca antes uma aproximação a Martin Luther King Jr. Assim, a ação do Luke Cage da Netflix não está fundada no desejo de vingança, como na $\mathrm{HQ}$, mas como num processo de tomada de consciência nascido do contato com o absurdo da violência no famoso bairro negro, sendo a partir dele que o herói vai encontrando o sentido da sua missão. Henry Hunter, o "Pop"37, é um renascido, alguém que abandonou a violência e que agora aconselha Cage a também abdicar do desejo de vingança.

Na série, Pop assume características análogas a de João Batista. Ele identifica o caminho e aponta-o para Cristo, mas depois desvanece. ${ }^{38}$ É da boca de Pop que Cage recebe o chamado de servir às pessoas do Harlem. Contudo, o futuro herói ainda é um estranho à realidade do Harlem, por isso é cauteloso e faz poucos amigos íntimos. $\mathrm{Na}$ série ele é reservado, atencioso e leitor de livros clássicos da cultura norte-americana, já nos quadrinhos ele era violento, gritão e boca suja. ${ }^{39}$ Enquanto o Cage dos quadri-

${ }^{32}$ Luke Cage, herói de aluguel, \#1, p. 20.

33 Do final do século XVIII até a Guerra da Secessão existiu uma rede de rotas clandestinas operadas por pessoas negras e brancas que apoiavam as pessoas escravizadas fugitivas do sistema escravocrata vigente nos estados do sul rumo aos estados do norte, ao Canadá e, em menor número, ao México. Essa rede de pessoas foi apelidada de "Underground Railroad" e esse foi o tema do romance de Colson Whitehead, que o trouxe ao Brasil em 2018.

${ }^{34}$ Luke Cage, herói de aluguel, \#1, p. 20.

35 As barbearias são um clássico dos filmes Blaxploitation. Na minissérie em quatro volumes da linha Noir, ambientada no começo do século XX, a Barbershop está presente no primeiro (p. 8-9) e no quarto volume (p. 14-19), numa imagem muito semelhante ao da Pop's Barbershop da série. Neste artigo, usamos a versão publicada no Brasil pela Panini num volume único (GLASS, Adam. Luke Cage Noir. São Paulo: Panini, out. 2013).

${ }^{36}$ Cf. TAYLOR, Clarence. Fight the Power: African Americans and the Long History of Police Brutality in New York City. New York: NYU Press, 2019. p. 68.

37 Pop ganhou esse apelido na juventude, quando era membro de uma gangue juntamente com Cornell Stokes, numa referência ao som que seus punhos faziam enquanto batia em alguém.

38 DERRY, Ken et al. Bulletproof Love: Luke Cage (2016) and Religion. Journal for Religion, Film and Media (JRFM), v. 3, n. 1, p. 123-155, 2017. p. 133.

39 Noutros momentos da vida do personagem Cage foi "suavizado", como quando nasceu a sua filha com Jessica Jones e o herói passou a dissimular os palavrões. Há que se perguntar se a suavização de Cage nessa série, que excluiu não apenas os palavrões, mas, também, muitos dos maneirismos e a violência típica do personagem, foi uma forma da produção evitar segmentar excessivamente o público da série. De igual modo, há de se perguntar em que medida essa suavização não poderia ser eventualmente também um modo de homogeneizar o personagem e de aproximá-lo de um ideal heroico hegemônico anglo-saxão 
nhos buscou seu uniforme numa loja de fantasia (um blusão amarelo com uma tiara prateada, cuja referência era explícita a Jim Brown, ícone blaxploitation do futebol americano $)^{40}$ e praticava a violência sem qualquer restrição, motivado pelo desejo de retaliação brutalmente alimentado na prisão, na obra da Netflix ele é um pacifista discreto que luta contra o sentimento de vingança e demora em decidir usar seus superpoderes em favor da comunidade, o que só ocorre quando amplia suas amizades e a realidade das pessoas do Harlem e, principalmente, o trágico assassinato de Pop, que o chama à ação.

\section{I was born by the river}

Enquanto em algumas séries é necessário algum esforço para reconhecer o elemento religioso presente nas narrativas, nessa obra da Marvel/Netflix encontramos numerosas referências bíblicas, muitas delas fundamentais para a teologia negra. Quando o recém-liberto Carl Lucas escolhe seu novo nome, relembra o texto preferido de seu pai, um pastor batista. É o verso de Lucas 4.18, no qual Jesus cita Isaías 61 dizendo: "O Espírito do Senhor está sobre mim, porque ele me ungiu para pregar boas novas aos pobres. Ele me enviou para proclamar liberdade aos presos e recuperação da vista aos cegos, para libertar os oprimidos". Esse também era o verso preferido do Rev. James Hal Cone, escritor do clássico Black Theology and Black Power, de $1969^{41}$, tanto que o entendia como a chave de interpretação do Evangelho de Lucas, já que nele encontramos o próprio Jesus definindo a natureza do seu ministério, como ação do próprio Deus indo às "profundezas da existência humana com o único propósito de destruir todos os tentáculos humanos da escravidão, libertando assim o ser humano dos principados e poderes ímpios que impedem seu relacionamento com Deus" ${ }^{\prime 2}$. A obra de Cristo é essencialmente de libertação, por isso ele se fez escravo para abrir "realidades da existência humana anteriormente fechadas ao ser humano"43. Cage, após a citação, relembra uma frase de seu pai que dizia: "Ninguém prende um

branco e protestante, isto é, em que medida retirar determinadas características do personagem ao longo de sua história nos quadrinhos não seria também um modo de abstrair sua identidade ou, antes, de tornar o personagem mais aceito.

40 NAMA, 2011, p. 62. Aos 45 minutos do episódio "Step in the arena" há uma referência explícita à diferença entre o novo e o velho Luke Cage. Nele, Carl Lucas veste uma roupa semelhante ao uniforme dos anos de 1970 e, ao olhar-se no vidro de um carro, diz: "You look like a damn fool".

41 James Cone publicou sua obra A Black Theology of Liberation em 1970, um ano depois de Rubem Alves ter publicado sua tese de doutorado Towards a Theology of Liberation. Apesar da precedência de Alves, há quem veja no livro de Cone a primeira sistematização da teologia da libertação, precedendo em pelo menos um ano a obra de Gustavo Gutiérrez.

42 "He is God Himself into the very depths of human existence for the sole purpose of destroying all human tentacles of slavery, thereby freeing man from ungodly principalities and powers that hinder his relationship with God." CONE, James H. Risks of faith: the emergence of a Black theology of liberation. Boston: Beacon, 1999. p. 7-8.

43 "His work is essentially one of liberation. Becoming a slave himself, he opens realities of human existence formerly closed to man." CONE, 1999, p. 8. 
homem que deseja ser livre" ${ }^{" 44}$, uma frase que dá o tom hermenêutico para a interpretação dessa citação bíblica no contexto da cena, unindo a lembrança de Carl Lucas à tradição da TNdL, num rompimento das amarras que o impedem de ser livre.

Cage é como um Lázaro, ou melhor, como um Lázaro lavador de pratos como o apelidou Cottonmouth ${ }^{45}$, alguém que ressurgiu da morte, mas, ao mesmo tempo, tal como na letra da música $A$ change is gonna come, de Sam Cooke, é um homem "nascido do rio", uma referência que qualquer credo-batista compreende, já que diz respeito ao segundo nascimento nas águas do batismo, um renascimento que afirma a autonomia da pessoa em sua luta por libertação. Na fuga de Seagate, ele renasceu nas águas, por isso o seu novo nome, mesmo que guarde "um pouco do antigo"46 (Luke, Lucas) e um pouco do que viveu na prisão, sendo aprisionado numa cela (Cage), aponta para uma mistura de renascimento pelo batismo e ressurreição. A nova identidade não apaga a anterior, mas a supera, fazendo com que a situação-limite da prisão injusta se torne um lugar concreto onde emergem novas possibilidades.

O tema da ressurreição é muito caro à teologia da libertação de Cone, sendo o paradigma de um modo de viver e de encarar a opressão. A ressurreição de Cristo "é a revelação de que Deus não é derrotado pela opressão, mas a transforma em possibilidade de liberdade" ${ }^{\prime 47}$. A vitória de Cristo sobre a morte apresenta um novo comportamento às pessoas que vivem numa sociedade opressiva. Dessa forma, se a morte já não tem a última palavra, o ostracismo social, a insegurança econômica e a tirania política também não têm mais poder de produzir medo e mudez. Nesse contexto, Cage é, como um novo Adão, aquele que, liberto da dor e da morte, agora combate a opressão, luta pela libertação de seu povo e serve como paradigma de uma nova vida sem medo. O seguimento como um reconhecimento na ressurreição de Cristo é exposto na série quando as pessoas vestem moletons com capuz furados de balas. O moletom, o uniforme de Cage na série, faz uma referência explícita ao jovem negro Trayvon Martin, de 17 anos, morto em fevereiro de 2012 com um tiro no peito pelo ex-segurança George Zimmerman. Dessa forma, a identificação com Cage é uma identificação com as vítimas da violência racial que mata jovens desarmados simplesmente por serem negros.

Voltemos aos experimentos de aprimoramento genético aplicados em Cage na Prisão da Seagate. O trabalho do cientista Noah Burstein nos faz lembrar o livro Acres of Skin: Human Experiments na Holmesburg Prison ${ }^{48}$, de 1998, escrito pelo jornalista Allen Hornblum. Nele, encontramos a denúncia acerca dos experimentos científicos feitos com cobaias humanas negras na Prisão Holmesburg, na Filadélfia, entre os anos de 1951 a 1974. Assim como os experimentos do dermatologista Albert Kligman na

44 T1, E4. A partir do minuto 42.

45 No episódio 5, Cottonmouth tenta insultar Cage chamando-o de "dishwasher Lazarus".

${ }^{46}$ Luke Cage, herói de aluguel, \#1, p. 22.

47 "His resurrection is the disclosure that God is not defeated by oppression but transforms it into the possibility of freedom". CONE, James H. A Black Theology of Liberation. 40th Anniversary edition. New York: Orbis, 2010. p. 125.

48 HORNBLUM, Allen M. Acres of Skin: Human Experiments at Holmesburg Prison. New York: Routledge, 2013. [versão digital]. 
Prisão Holmesburg contribuíram para tornar a enxertia de pele possível, o experimento de Burstein previa benefícios para a humanidade como um todo, sem, contudo, importar-se com o preço negro a ser pago. Na HQ de 1972, o médico de Seagate argumentou com Cage dizendo: "É arriscado, esforços parecidos já custaram vidas, mas, se tivermos sucesso, toda a humanidade se beneficiará"49.

O corpo negro objetivado, que pode pagar o preço pelo progresso científico, ainda que não se beneficie dele, é o mesmo corpo segregado e subjugado por interesses econômicos brancos até hoje. É a partir desse corpo caluniado pelo racismo que a TNdL construirá sua base epistemológica, desconsiderando o universalismo desencarnado de René Descartes e afirmando, como nas palavras de James H. Cone, que "quer os teólogos reconheçam isso ou não, todas as teologias começam com a experiência" ${ }^{50}$, nesse caso, a experiência da negritude num país racista.

Para a teologia negra, há um vínculo existencial entre a pessoa teóloga e o contexto sociopolítico em que ela está inserida, de forma que não há como fazer teologia sem fundamentá-la na subjetividade da nossa biografia e na nossa experiência atual. Daí que Cone use da sua própria história para questionar o estatuto ontológico dado ao corpo negro pelo discurso branco. Ao relembrar sua experiência na Igreja Metodista Episcopal Africana Macedônia, no Arkansas, Cone narrou que "decorridos os seis dias da semana nos quais eles eram considerados como nada pelos dirigentes da sociedade branca, no sábado, o sétimo dia da semana, o povo negro ia à igreja a fim de experimentar uma outra definição de sua humanidade" "51. Essa era uma reação à tentativa branca de definir a realidade negra, afirmando uma teologia segregacionista capaz de proclamar a escravidão como vontade de Deus. A partir dessa teologia opressora, esse cristianismo branco esperava que o povo negro tivesse "prazer em arar os seus campos, limpar as suas casas, aparar a sua grama e trabalhar em suas serrarias" ${ }^{\prime \prime 2}$. Seguindo essa lógica terrível, qualquer sinal de desprazer com o estado predestinado de ser inferior era entendido como arrogância diante de Deus e rapidamente exigia uma punição que os colocasse no "lugar". As reflexões teológicas de Cone são inseparáveis da experiência na cidade segregada de Bearden, por isso ele dizia:

"Aquilo que escrevo é expelido de meu sangue" e do sangue dos negros de Bearden e de qualquer outro lugar que vê o que eu vejo, sente o que eu sinto e ama o que eu amo. Essa é a razão pela qual a teologia negra difere em perspectiva, conteúdo e estilo da tradição teológica ocidental transmitida desde Agostinho até Barth. Minha teologia não será a mesma que as de meus colegas brancos do Union Theological Seminary, porque nossa experiência é diferente ${ }^{53}$.

49 Luke Cage, herói de aluguel, \#1, 1972, p. 14.

50 "Theologians acknowledge it or not, all theologies begin with experience." CONE, James H. Said I Wasn't Gonna Tell Nobody: The Making of a Black Theologian. New York: Orbis, 2018. Disponível em: $<$ https:// books.google.com.br/books?id=365wDwAAQBAJ\&dq $>$.

${ }^{51}$ CONE, James H. O Deus dos oprimidos. Trad. Josué Xavier. São Paulo: Paulinas, 1985. p. 21.

${ }^{52}$ CONE, 1985 , p. 10.

${ }^{53}$ CONE, 1985, p. 11. 
Os cristãos e as cristãs das igrejas negras buscavam por meio da fé "passar à outra margem do rio", aquela "realidade 'sobrenatural' que está fora do alcance das limitações apavorantes deste mundo" 54 . Cage é, nesse sentido, aquele que chegou à outra margem, mas lá não encontrou a terra prometida, não havia as ruas de ouro dos antigos cânticos, e sim o mesmo impulso subjugador que ainda "lincha" os corpos negros $^{55}$, ainda que com outros métodos.

Se a era do linchamento chegou ao fim, não chegou a da constante ameaça existencial imposta ao povo negro. Tanto que James Cone, no livro The Cross and the Lynching Tree, descortina algumas imagens negras sobre Cristo, relembrando a obra de William Edward Burghardt “W. E. B.” Du Bois, que num conto faz a crucial pergunta: como um Cristo negro seria recebido nos Estados segregados do sul no início do século XX? Por meio de uma parábola chamada “The Gospel of Mary Brown”, Du Bois apresenta um Cristo chamado Joshua, um homem negro que, mesmo pregando o amor, acaba sendo linchado por uma multidão enfurecida numa pequena cidade do Texas. Essa narrativa apresenta um elemento cristológico importante: a relação análoga entre o madeiro da cruz e o da árvore de linchamento. Cone, ao interpretar a parábola de Du Bois, afirma que "a cruz e o linchamento são separados por quase dois mil anos. Um é o símbolo universal da fé cristã; o outro é o símbolo por excelência da opressão negra na América" ${ }^{56}$. Se o linchamento, enquanto estratégia de opressão, foi superado ${ }^{57}$, o mesmo não se pode dizer da violência racial, que se mantêm como estratégia de terror para o povo negro. É exatamente na opressão e no terror que a cruz, a árvore de linchamento ou o joelho sufocante sobre o pescoço são imagens que remetem à mesma realidade terrífica, de uma violência que se impõe sem deixar lugar para fuga. A supremacia branca atualiza o autoritarismo do poder do Estado Romano, lembrando-nos que não se pode esvaziar a cruz, desligando-a da brutalidade concreta promovida contra as pessoas oprimidas, sob pena de fazer com que o triunfalismo de uma cruz sem sofrimento permita o convívio pacífico entre o cristianismo e a opressão sistêmica.

${ }^{54}$ CONE, 1985, p. 9.

${ }^{55}$ Colson Whitehead, com sua imensa capacidade narrativa, nos traz à memória cenas dessa barbárie ao narrar o momento em que a protagonista Cora, uma jovem órfã que foge de uma plantação de algodão na Geórgia, vê "homens pendurados em árvores, deixados ao relento para urubus e corvos. Mulheres escarnadas até os ossos pela chibata. Corpos vivos e mortos sendo queimados em piras. Pés cortados para evitar fuga e mãos decepadas para cessar o roubo" (WHITEHEAD, Colson. The Underground Railroad: Os caminhos para a liberdade. Trad. Caroline Chang. Rio de Janeiro: HarperCollins Brasil, 2017. [versão digital]).

56 "The cross and the lynching tree are separated by nearly two thousand years. One is the universal symbol of the Christian faith; the other is the quintessential symbol of black oppression in America." CONE, James H. The Cross and the Lynching Tree. New York: Orbis, 2013. p. 8.

57 Cabe destacar que somente em fevereiro de 2020 o linchamento foi tornado crime federal, por meio da Lei Emmett Till. Isso ocorreu 120 anos depois do projeto de lei do deputado federal George Henry White, o único negro no Congresso americano no início do século XX, propor a criminalização dessa barbárie. 


\section{$O$ anticristo e a questão da justiça}

A primeira temporada da série pode ser dividida em duas partes. Na primeira, que vai até o episódio sete, a trama está centrada no conflito entre Cage e Cornell Stokes, um mafioso local apelidado de Cottonmouth, dono da casa de jazz Harlem's Paradise, e sua prima Mariah Dillard, uma vereadora corrupta que hipocritamente fala de um renascimento do Harlem, usando a retórica de "manter o Harlem negro" para controlar o bairro e seus moradores. No segundo episódio da série, ambos conversam no Harlem's Paradise sobre a essência do poder. Para Dillard, o poder está no respeito oriundo da influência política e da capacidade de estabelecer um legado, mas Cottonmouth a lembra da dependência entre o poder político da vereadora e o dinheiro oriundo do crime organizado. A figura de Cage contrasta com essas relações de poder, pois, tal como o Cristo do lava-pés, Cage é aquele cujo poder está em servir, ou melhor, está em um poder a serviço da justiça. Sua ação aponta para a mensagem do Reino que "ataca o próprio centro do desejo humano de definir sua própria existência à luz de seu interesse próprio, ao preço da escravidão de seu irmão"s8.

A segunda parte começa com a morte de Cornell, assassinado por sua prima quando ele a acusa de desejar o abuso sexual de que foi vítima na adolescência. É nesse momento que Diamondback, o segundo antagonista de Luke Cage, surge. Diamondback é o meio-irmão de Cage, Willis Stryker, que deseja vingar-se do fato de seu irmão mais novo ter sido o filho "escolhido", enquanto ele vivia na sombra de um pai ausente que o abandona na juventude, permitindo que seja enviado para um reformatório. ${ }^{59}$

Para Cone, "a teologia é sempre identificada com uma comunidade particular. Ela é identificada com aqueles que infligem a opressão ou com aqueles que são suas vítimas. Uma teologia desta última é a teologia cristã autêntica e uma teologia da primeira é a teologia do anticristo" ${ }^{\circ 0}$. Seguindo essa premissa, lancemos o nosso olhar sobre os dois personagens que interpretam o anticristo na primeira temporada, Cottonmouths e Diamondbacks. Ambos podem ser entendidos como personificação da serpente de Gênesis 3 em sua promoção da morte e sua luta contra a esperança, ferindo o calcanhar da humanidade. A primeira em sua luta desmedida por poder, a segunda motivada pela amargura diante do abandono do pai, mas ambos se opõem ao "Cristo negro" e se posicionam em favor de um sistema corrupto e corruptor, oposto à justiça e sustentador da opressão.

A relação dos dois irmãos, Cage e Stryker, o filho "milagrosamente concebido" e o filho da vergonha, remete-nos diretamente à história de Caim e Abel em Gênesis,

58 "It reality the message of the Kingdom strikes at the very center of man's desire to define his own existence in the light of his own interest at the price of his brother's enslavement." CONE, 1999, p. 8.

${ }^{59} \mathrm{Na}$ juventude os dois irmãos foram presos e acusados de roubo de um Chevrolet Corvette. O Rev. James conseguiu convencer o juiz a trocar a pena de Carl pelo alistamento no corpo de Fuzileiros Navais, sem oferecer a mesma ajuda ao seu outro filho, que foi condenado a um centro de detenção juvenil.

60 "Theology is always identified with a particular community. It is either identified with those who inflict oppression or with those who are its victims. A theology of the latter is authentic Christian theology, and a theology of the former is the theology of the anti-Christ." (CONE, 2010, p. 6). 
tanto que a frase emblemática do verso de Gênesis 4.9 (“acaso sou eu o guarda de meu irmão?") é o texto bíblico mais citado da série. Diamondback, que também era filho de pastor, cita muitos textos bíblicos e, tal como a serpente de Gênesis, distorce a Bíblia para justificar seu antagonismo na série. No episódio 8 da primeira temporada, quando mantinha a detetive Misty sob sua mira, Diamondback cita 1 Pedro 5.8 dizendo: "Diabo, vosso adversário, anda em derredor, bramando como leão, buscando a quem possa tragar". Na cena seguinte, ele acusa Cage de ser um falso ídolo, um bezerro de ouro, em referência ao ídolo feito por Arão no deserto (Êxodo 32) ${ }^{61}$ Em conversa com Shades, Diamondback cita Provérbios 18.24 ao falar de sua amizade com Cottonmouths, falando dele como "um amigo mais chegado do que um irmão".

No episódio 10, Cage cita Gênesis 4.9. O mesmo verso aparece no episódio seguinte na boca de Diamondback, quando, segurando a Bíblia que ganhou de herança da sua mãe, conta a sua história para Damon Boone, o político rival de Mariah Dillard, e diz:

Deus me conquistou com Gênesis. A história de Caim e Abel. Quando Deus perguntou a Caim onde Abel estava depois de tê-lo matado. Caim perguntou: "Sou eu o guardador do meu irmão?". Veja, eu achava que era um lance legal, criado por Wesley Snipes em New Jack City. Acontece que é real. Então, depois de eu matar Luke Cage, ficarei sobre ele e direi: "Sim, eu sou".

Cage retoma o texto de Gênesis no episódio 13, negando a possibilidade de ser guardião de seu irmão. Foi ao decidir não ser mais guardião de Diamondback que Cage reafirma a sua missão de ser herói do Harlem, o guardião dos seus iguais.

Tal como outros personagens das aventuras de super-heróis, como Superman, Luke Cage é uma figura messiânica. Enquanto o parentesco cristológico do filho de Krypton está na morte sacrificial e ressurreição redentora, Cage aponta para a encarnação de Cristo, numa recapitulação do ministério de Cristo às pessoas pobres e oprimidas, como se pode notar na frase do rapper Method Man, ao explicar o porquê da fuga de Luke Cage: "Ser à prova de bala vai sempre vir depois de ser negro"62. Ele é plenamente humano, exposto ao racismo como qualquer outro, mas a sua pele é impenetrável, o que aponta para uma realidade escatológica, para um reino em que a pele negra já não é alvejada por balas.

No segundo episódio da primeira temporada, há um diálogo entre Pop e Cottonmouth, no qual Stokes defende a ideia "old school" presente em Levítico 24.20 (“olho por olho e dente por dente"). Ao ser questionado por Pop sobre a regra áurea de

${ }^{61}$ O Rev. James Lucas, pai de Luke Cage, segue essa mesma ideia no primeiro episódio da segunda temporada dizendo que "a adoração a Luke Cage chegou a proporção de bezerro de ouro" (4:58). Contrariando tal idolatria, o reverendo afirma: "Luke Cage não é nada além de um homem e há uma razão pela qual não adoramos homens: porque somos fracos, sujeitos à tentação, ego, vaidosos, rancorosos. Oh sim, Deus sabe que somos rancorosos. A pele à prova de balas não muda a natureza" (6:06). A crítica do Rev. James Lucas não é sem sentido, pois aponta para o problema clássico do messianismo: o desmoronamento do empenho pessoal e comunitário por libertação, que é substituído por uma esperança infantil numa figura libertadora.

62 T01, E12, 28:02. 
dar a outra face (Mateus 5.38-42), Cottonmouth sentencia: "Jesus salva, eu não"63. De forma antagônica a Cottonmouth, Luke Cage é aquele que com o próprio corpo oferece a salvação às pessoas, como nas muitas vezes que usou o corpo como escudo para salvar pessoas dos tiros. A partir da natureza polissêmica da cultura POP, encontramos muitas representações cristológicas aplicadas a Cage: ele é pobre, poucos sabem do seu passado, ressurge da morte e já não a teme, o instrumento usado para tentar matá-lo é uma bala chamada Judas. Na abertura da série, não há como deixar de notar a alusão à clássica representação de Cristo no minuto 52 do primeiro episódio, quando o capuz combinado com o cavanhaque relembra as clássicas imagens de Cristo, dando a ele a face de um Christus Victor, que vence a morte e a escravidão. O Cristo negro da série é aquele cujo corpo impenetrável o libertou da morte e agora lhe dá a capacidade de levar o Shalom às pessoas pobres e oprimidas. Sua natureza sobrenatural não o destitui de sua condição de pessoa negra num país que tem como tradição "destruir o corpo negro" ${ }^{64}$, por isso a consciência do evangelho se dá à luz da opressão ao povo negro, o que lhe concede "o poder necessário para romper as cadeias de opressão" ${ }^{95} \mathrm{e}$ promover o anúncio de Lucas 7.22, tal como é lida por Cone, como a

irrupção de uma nova era, uma era que tem a ver com a ação de Deus na história em favor da salvação do ser humano. É uma era de libertação, em que "os cegos veem, os coxos andam, os leprosos são purificados, os surdos ouvem, os mortos ressuscitam e aos pobres são pregadas as boas novas" ${ }^{\prime \prime 6}$.

Mesmo com uma relação agônica que permeia a série, é interessante notar que a produção não cai na cilada de moralizar a cor da pele, numa luta entre pessoas brancas opressoras e pessoas negras oprimidas. O sistema de opressão é representado tanto por gente negra quanto por gente branca. O mesmo acontece quando selecionamos as pessoas que lutam pela justiça. Usando uma linguagem da TNdL, podemos dizer que a maldade e a bondade são daltônicas, não distinguem cor. A opressão, contudo, tem uma preferência terrível pela cor negra. Daí que a série também não se traia com uma falsa noção de igualdade, da qual as comunidades afrodiaspóricas são constantemente excluídas. A série não deixa de estar situada em uma sociedade ainda marcada pela segregação racial, na qual a herança do colonialismo e da escravidão nos conduzem ao clamor por libertação.

A série, tal como o universo criado nos quadrinhos, transita num espaço formado por pessoas que são a expressão clara da máxima luterana do "simul justus et

63 T01, E02, 12:29.

${ }^{64}$ COATES, Ta-Nehisi. Entre o mundo e eu. Trad. Paulo Geiger. Rio de Janeiro: Objetiva, 2015. p. 107.

${ }^{65}$ CONE, 2010, p. 5.

66 "It means the irruption of a new age, an age that has to do with God's action in history on behalf of man's salvation. It is an age of liberation, in which 'the blind receive their sight, the lame walk, the lepers are cleansed, the deaf hear the dead are raised up, the poor have the good news preached to them" CONE, 1999 , p. 8. 
peccator" ${ }^{" 67}$. Expressando uma lógica capaz de comportar as contradições, de forma que mesmo as representações do mal não são destituídas de historicidade, de contexto existencial que molda suas ações. Quando no final da segunda temporada Luke assume sua função de manter o equilíbrio entre o bem e o mal, ele também adentra de modo mais explícito nesse mundo cinza, longe do maniqueísmo dos dois extremos, e assume o papel de rei do Harlem. Nesse momento, ele cede ao "cântico de sereia" do Harlem's Paradise ${ }^{68} \mathrm{e}$ se porta como um gangster, numa cena muito semelhante àquela na qual Michael Corleone assume o posto que lhe fora deixado por seu pai, no final do filme $O$ Poderoso Chefão (1972). De certa forma, essa cena nos faz pensar se o Cristo Harlem cedeu à tentação, validando a narrativa distorcida acerca do poder.

\section{Conclusão}

Luke Cage traz para as telas uma crítica contundente da teologia negra da libertação, nomeadamente, quando diz que o corpo negro é um corpo político, capaz de colocar em aporia o cristianismo branco que durante tanto tempo validou ou, no mínimo, esquivou-se de condenar o racismo ${ }^{69} \mathrm{~A}$ cruz e a árvore do linchamento, o madeiro e o pelourinho, o corpo na cruz e o corpo alvejado no chão, ambos traduzem os efeitos de uma mesma consciência necrófila que faz com que a pessoa opressora perca o contato com o mundo vivo e necessite transformar tudo ao seu redor em objetos de seu domínio. ${ }^{70}$ Essa consciência possessiva levou essas pessoas a se afogarem na posse como condição de ser. Uma condição desumanizada e desumanizadora que gera o sádico impulso de privar os demais humanos daquilo que é essencial à vida: o poder da liberdade. Assim sendo, o Cristo negro atualiza o que Cone escreveu no prefácio da edição de 1970: "Qualquer mensagem que não esteja relacionada com a libertação dos pobres em uma sociedade não é uma mensagem de Cristo. Qualquer teologia que é

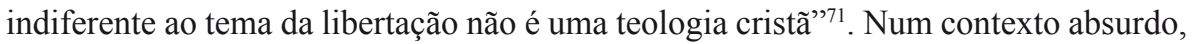
em que ainda se faz necessário afirmar que vidas negras importam, Luke Cage alia-se ao "sopro antirracista do Espírito"72 afirmando a humanidade negra contra a opressão de uma estrutura racista que silencia, marginaliza e promove a morte de quem não se encaixa em sua construção autocentrada de mundo.

${ }^{67}$ Cf. LUTERO, Martinho. A Epístola do Bem-Aventurado Apóstolo Paulo aos Romanos. In: Obras Selecionadas. São Leopoldo: Sinodal; Porto Alegre: Concórdia, 2003. v. 8, p. 227-330.

${ }_{68}$ Apesar de não ter um nome que remeta à serpente do Éden, Mariah é a que melhor personifica o caráter enganador presente nessa figura mitológica. No episódio final da segunda temporada ela explica como o Harlem's Paradise seria um canto de sereia para Cage: "O filho do pastor vai achar que pode usar o poleiro para mudar as coisas, para controlá-las, mas, no final, ele é que será mudado” (T02, E13, 59:33).

${ }_{69}$ Merece destaque aqui a crítica de James Cone à Reinhold Niebuhr, que "permaneceu confinado em seu escritório no Union Seminary ensinando ética social cristã, nunca arriscando a vida na luta pela justiça" (CONE, 2013, p. 71), enquanto Martin Luther King Jr. se tornou um mártir no movimento dos direitos civis.

${ }^{70}$ FROMM, Erich. El Corazón del Hombre. México: Fondo de Cultura Económica, 1967. p. 41.

${ }^{71}$ CONE, 2010, p. 9.

${ }^{22}$ PACHECO, Ronilso. Teologia negra: o sopro antirracista do Espírito. Brasília: Novos Diálogos; São Paulo: Recriar, 2019. 


\section{Referências}

COATES, Ta-Nehisi. Entre o mundo e eu. Trad. Paulo Geiger. Rio de Janeiro: Objetiva, 2015. CONE, James H. A Black Theology of Liberation. 40th Anniversary edition. New York: Orbis, 2010. CONE, James H. O Deus dos oprimidos. Trad. Josué Xavier. São Paulo: Paulinas, 1985.

CONE, James H. Risks of faith: the emergence of a Black theology of liberation. Boston: Beacon, 1999.

CONE, James H. The Cross and the Lynching Tree. New York: Orbis, 2013.

CONE, J. H. Said I Wasn't Gonna Tell Nobody: The Making of a Black Theologian. New York: Orbis, 2018. Disponível em: <https://books.google.com.br/books?id=365wDwAAQBAJ\&dq > DERRY, Ken et al. Bulletproof Love: Luke Cage (2016) and Religion. Journal for Religion, Film and Media (JRFM), v. 3, n. 1, p. 123-155, 2017.

EWING, Al; LAND, Greg; LEISTEN, Jay. Mighty Avengers, v. 2 \#11, ago. 2014.

FROMM, Erich. El Corazón del Hombre. México: Fondo de Cultura Económica, 1967.

GLASS, Adam. Luke Cage Noir. São Paulo: Panini. Out. 2013.

HORNBLUM, Allen M. Acres of Skin: Human Experiments na Holmesburg Prison. New York: Routledge, 2013. [versão digital]

LEE, Stan; GOODWIN, Archie; ROMITA, John. Luke Cage, herói de aluguel, \#1, 1972.

LUTERO, Martinho. A Epístola do Bem-Aventurado Apóstolo Paulo aos Romanos. In: Obras Selecionadas. São Leopoldo: Sinodal; Porto Alegre: Concórdia, 2003. v. 8, p. 227-330.

MARVEL - Luke Cage. Direção: Cheo Hodari Coker. Los Gatos: Netflix, 2016. Disponível em: $<$ https://www.netflix.com/title/80002537?so=su>. Acesso em: 03 fev. 2020.

ONU Mulheres. 2018. Disponível em: $<\mathrm{http}$ ://www.onumulheres.org.br/noticias/23-mil-jovens-negros-assassinados-por-ano-e-um-escandalo-diz-nadine-gasman-representante-da-onu-mulheres/>. Acesso em: 02 jun. 2019.

NAMA, Adilifu. Super black: American pop culture and black superheroes. Austin: University of Texas Press, 2011.

PACHECO, Ronilso. Teologia negra: o sopro antirracista do Espírito. Brasília: Novos Diálogos; São Paulo: Recriar, 2019.

REBLIN, Iuri Andréas. Histórias em Quadrinhos: perspectivas religiosas e possibilidades hermenêuticas. São Leopoldo: EST, 2019.

REBLIN, Iuri Andréas. Método cartográfico-crítico para análise de artefatos da cultura pop a partir da área de ciências da religião e teologia. Rever: Revista de Estudos da Religião, v. 20, n. 3, p. 11-26, set./dez. 2020.

SHEFFIELD, R. 'Luke Cage': Meet the First Black Lives Matter Superhero. Rolling Stone, out. 2016. Disponível em: $<$ https://www.rollingstone.com/tv/tv-news/luke-cage-meet-the-first-black-lives-matter-superhero-112895/>. Acesso em: 02 jun. 2019.

TAYLOR, Clarence. Fight the Power: African Americans and the Long History of Police Brutality in New York City. New York: NYU Press, 2019.

TOLIVER, Stephanie. Unlocking the Cage: Empowering Literacy Representations in Netflix's Luke Cage Series. Journal of Adolescent \& Adult Literacy, v. 61, n. 6, p. 621-630, maio/jun. 2018. WHITEHEAD, Colson. Colson Whitehead, um dos maiores escritores da atualidade. Entrevista concedida a Jorge Pontual. Milênio - Globo News, 29 de maio de 2017.

WHITEHEAD, Colson. The Underground Railroad: Os caminhos para a liberdade. Trad. Caroline Chang. Rio de Janeiro: HarperCollins Brasil, 2017 